http://dx.doi.org/10.5012/bkcs.2014.35.4.1082

\title{
Fast High-throughput Screening of the H1N1 Virus by Parallel Detection with Multi-channel Microchip Electrophoresis
}

\author{
Peng Zhang, ${ }^{\dagger}$ Guenyoung Park, ${ }^{\dagger}$ and Seong Ho Kang ${ }^{\dagger \dagger}, *$ \\ ${ }^{\dagger}$ Department of Chemistry, Graduate School, Kyung Hee University, Yongin-si, Gyeonggi-do 446-701, Korea \\ ${ }^{\ddagger}$ Department of Applied Chemistry, College of Applied Science, Kyung Hee University, Yongin-si, Gyeonggi-do 446-701, Korea \\ *E-mail:shkang@khu.ac.kr \\ Received November 20, 2013, Accepted December 16, 2013
}

\begin{abstract}
A multi-channel microchip electrophoresis (MCME) method with parallel laser-induced fluorescence (LIF) detection was developed for rapid screening of H1N1 virus. The hemagglutinin (HA) and nucleocapsid protein (NP) gene of H1N1 virus were amplified using polymerase chain reaction (PCR). The amplified PCR products of the H1N1 virus DNA (HA, 116 bp and NP, $195 \mathrm{bp}$ ) were simultaneously detected within $25 \mathrm{~s}$ in three parallel channels using an expanded laser beam and a charge-coupled device camera. The parallel separations were demonstrated using a sieving gel matrix of $0.3 \%$ poly(ethylene oxide) $\left(M_{\mathrm{r}}=8,000,000\right)$ in $1 \times \mathrm{TBE}$ buffer $(\mathrm{pH}$ 8.4) with a programmed step electric field strength (PSEFS). The method was 20 times faster than conventional slab gel electrophoresis, without any loss of resolving power or reproducibility. The proposed MCME/PSEFS assay technique provides a simple and accurate method for fast high-throughput screening of infectious virus DNA molecules under $400 \mathrm{bp}$.
\end{abstract}

Key Words : Influenza A (H1N1) virus, Multi-channel microchip electrophoresis, Parallel detection, Highthroughput screening

\section{Introduction}

Influenza $A(\mathrm{H} 1 \mathrm{~N} 1)$ virus is one of the most common pathogenic viruses in humans and causes the infectious respiratory disease influenza. ${ }^{1}$ This highly infectious disease tends to occur most frequently in the elderly and children and causes significant morbidity and mortality; in addition to being highly infectious, the virus can rapidly spread and become a major public health menace. ${ }^{2}$ In recent years, to prevent and control epidemic disease, various protein- and gene-based detection methods have been used in the clinical and laboratory diagnosis of $\mathrm{H} 1 \mathrm{~N} 1$ virus. ${ }^{3-8}$ For instance, protein-based methods such as the rapid influenza $A$ virus diagnostic test (RIDT), which is based on immunochromatographic lateral flow tests and uses monoclonal antibodies directed against the nucleocapsid protein (NP) of influenza virus, has been widely used in influenza diagnoses. ${ }^{3}$ However, the RIDT assay cannot distinguish between influenza $A$ virus subtypes and has limited accuracy $(<70 \%) .{ }^{4,5}$ In comparison, gene detection methods based on polymerase chain reaction (PCR) assays are able to detect the influenza virus with $97 \%$ accuracy. ${ }^{6-8}$ In addition, by using specific primers and probes, the different subtypes of influenza $A$ can be discriminated. ${ }^{6-10}$ However, current PCR methods continue to rely heavily on slab gel electrophoresis (SGE) analysis, which requires several hours to obtain results and is extremely low-throughput, making this technique unsuitable for a large number of samples. ${ }^{11}$ Even though real-time PCR (RT-PCR) methods may decrease analysis time, they require special thermo-cyclers equipped with an expensive and sensitive camera and well-designed primers. ${ }^{2}$ The biochip method based on microarrays for analyzing the influenza virus is complex and also very expensive. ${ }^{12}$ Hence, a highthroughput screening method which can be used to diagnosis of the H1N1 virus is needed.

Capillary electrophoresis (CE) and microchip electrophoresis (ME) are powerful methods of separation, with high-performance separation capacities for a variety of biomolecules attributable to their high speed, reduced chemical consumption and low cost of manufacturing. ${ }^{13-18}$ However, using single capillaries in conventional CE limits its throughput; therefore, by incorporating many capillaries into a single $\mathrm{CE}$ instrument, the capillary array electrophoresis (CAE) system was developed to increase throughput. ${ }^{19}$ However, as the number of capillaries increases, it becomes more difficult to control the injection of the sample and to simultaneously detect signals from all of the capillaries. On the other hand, integrating many separation channels onto a single wafer to form a multi-channel microchip electrophoresis (MCME) system can provide a much more stable, precise and userfriendly technique with extremely high throughput. ${ }^{20}$ To date, many glass- and polymer-based MCME devices have been developed and applied in the separation of protein mixtures as well as in drug screening. Compared with conventional SGE and CAE systems, these MCME separation assays provide remarkably higher throughput and more simplified operation processes. ${ }^{21-26}$ Therefore, the MCME is a promising candidate for high-throughput methods and can be used in H1N1 virus-related DNA analysis.

In this study, we developed a fast and high-throughput MCME separation method using programmed stepped electric field strength (PSEFS) to analyze H1N1 virus DNA 
molecules. The MCME/PSEFS was used to simultaneously detect separations in three different parallel channels using laser-induced fluorescence detection for high-throughput analysis without a loss in resolution.

\section{Experimental}

Reagents and Materials. $1 \times$ TBE buffer $(0.089 \mathrm{M}$ Tris, $0.089 \mathrm{M}$ borate, and $0.002 \mathrm{M}$ EDTA, $\mathrm{pH}$ 8.4) and $1 \times \mathrm{TAE}$ buffer (0.04 M Tris-acetate, $0.001 \mathrm{M}$ EDTA, pH 8.4) were prepared by dissolving a premixed powder (Ameresco, Solon, OH, USA) in ultra-pure water. The dynamic coating matrix of the microchip was made by dissolving $1.0 \% \mathrm{w} / \mathrm{v}$ poly(vinyl pyrolidone) (PVP, $\left.M_{\mathrm{r}}=1,000,000\right)$ (Polyscience, Warrington, England) in a $1 \times$ TBE buffer with $0.5 \mathrm{ppm}$ ethidium bromide (EtBr) (Molecular Probes, Eugene, OR, USA). The PVP solution was shaken for $\sim 5$ min to dissolve the PVP completely, which was then left to stand for $2 \mathrm{~h}$ to remove any bubbles. The poly(ethylene oxide) $\left(\mathrm{PEO}, M_{\mathrm{r}}=\right.$ $8,000,000$ ) (Sigma, St. Louis, MO, USA) solution used as sieving matrix was made by dissolving PEO in a $1 \times$ TBE buffer with $0.5 \mathrm{ppm}$ EtBr. The PEO solution was stirred overnight to dissolve the polymer and to remove any bubbles.

Preparation of PCR Products. H1N1 virus DNA samples were acquired from Ahram Biosystem Incorporated (Seoul, Korea). They were amplified by palm PCR using a PalmTaq ${ }^{\text {TM }}$ High-speed PCR kit (Ahram Biosystem Inc., Seoul, Korea). To amplify the hemagglutinin (HA) and nucleocapsid protein (NP) gene, primers for HA (forward: 5'-GTG CTA TAA ACA CCA GCC TCC CA-3' and reverse: 5'-CGG GAT ATT CCT CAA TCC TGT GGC-3') and NP (forward: 5'-GCA CGG TCA GCA CTT ATT CTA AG-3' and reverse: 5'-GTG AGC TGG GTT TTC ATT TGG TC-3') were used. First, 20 $\mu \mathrm{L}$ of PalmTaq ${ }^{\mathrm{TM}} 5 \times \mathrm{HS}$ buffer solution $\left(1.5 \mathrm{mM} \mathrm{MgCl} \mathrm{Mg}_{2}\right.$ final concentration) was added to $62.6 \mu \mathrm{L}$ of sterilized distilled water, followed by $5 \mu \mathrm{L}$ each of forward primer $(10$ $\mu \mathrm{M})$, reverse primer $(10 \mu \mathrm{M})$, and template DNA $(\leq 200$ $\mathrm{mg}$ ). Following the addition of $2 \mu \mathrm{L}$ of dNTP mixture (10 $\mathrm{mM}$ each dNTP) and $0.4 \mu \mathrm{L}$ of PalmTaq ${ }^{\mathrm{TM}}$ High-speed DNA polymerase ( 5 unit/ $\mu \mathrm{L})$, the total amount of the reaction mixture was divided into five sample tubes. Before the mixed sample solution was incubated, the sample tubes were centrifuged for $1 \mathrm{~min}$ at 5,000-6,000 rpm. The following protocols programmed in the Palm PCR F1-12 device (Ahram Biosystem Inc., Seoul, Korea) were performed: denaturation temperature of $98.0^{\circ} \mathrm{C}$, annealing temperature of $58.0^{\circ} \mathrm{C}$, and the number of amplification cycles was set as 30 . The final PCR products of HA and NP were mixed to confirm the separation of the mixture sample (HA:NP $=1: 1$ ).

Slab Gel Electrophoresis. Amplified DNA molecules were identified by SGE in 2.0\% agarose gel (Sigma, St. Louis, MO, USA) using a $1 \times$ TAE buffer, stained with $\mathrm{EtBr}$, and then photographed using a still video documentation system (MC2000, CoreBio, Soul, Korea). The sizes of the DNA products were determined relative to a $100-b p$ DNA ladder. (a)

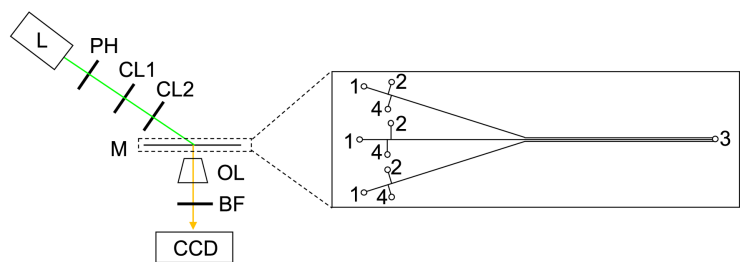

(b)

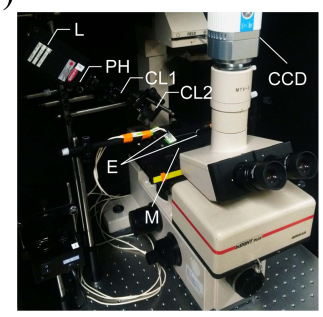

(c)

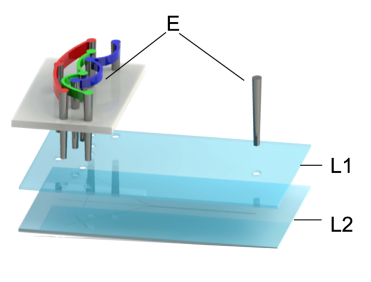

Figure 1. Multi-channel ME with laser-induced fluorescence (LIF) detection systems. (a) Schematic diagram of the LIF detection system and multi-channel microchip. (b) Physical layout of the MCME system. (c) Two-layer structure of the multichannel microchip and setup of the electrodes. Indication: L, laser; PH, pin hole; CL1, first cylindrical lens; CL2, second cylindrical lens; M, multichannel microchip; OL, objective lens; BF, band-pass filter; CCD, charge-coupled device; E, electrodes; L1, layer 1; L2, layer 2; reservoir 1, buffer inlet; reservoir 2, sample outlet; reservoir 3, buffer waste; reservoir 4 , sample inlet.

Lab-built Multi-channel Microchip Electrophoresis System. A lab-built multi-channel ME system was produced on a microscope (IMT-2, Olympus, Tokyo, Japan) with an objective lens $(10 \times / 0.25$ N.A.; Olympus, Tokyo, Japan) (Figures 1(a) and 1(b)). A diode-pumped solid-state laser (excitation at $532 \mathrm{~nm}$; Shanghai Laser \& Optics Century, Shanghai, China) was used as an excitation source. Two cylindrical lenses were used to focus the laser beam on the central part of the detection area of the multi-channel microchip. The microscope was used to collect and transmit the fluorescence signal from the analyte to the detector, which consisted of a charge-coupled device (CCD) detector (01EXI-BLU-R-F-M-14-C, QImaging, Surrey, Canada). A bandpass filter (35-5081, 600.0 $\pm 8.0 \mathrm{~nm}$; Ealing Catalog, Rocklin, CA, USA) was placed in front of the CCD camera to filter out irrelevant wavelengths. Detection region images from the CCD camera were analyzed using Image-Pro Plus (Version 7.0, Media Cybernetics, Bethesda, MD, USA) software to obtain fluorescence intensity curves. The glass-based multichannel microchip was designed as a two-layer structure (Figures 1(a) and 1(c)). Three separation channels (i, ii, and iii, $50 \mathrm{~mm}$ wide and $10 \mathrm{~mm}$ deep, $6.5 \mathrm{~cm}$ long) with a double-T sample injection pattern were etched onto a glass wafer (layer $1,7.5 \mathrm{~cm}$ long and $2.5 \mathrm{~cm}$ wide) individually. To prevent contamination of the sample, another glass wafer (layer $2,7.5 \mathrm{~cm}$ long and $2.5 \mathrm{~cm}$ wide) with 10 reservoirs $(2.0 \mathrm{~mm}$ in diameter) was agglutinated onto the first layer. Platinum wires $(0.4 \mathrm{~mm}$ in diameter $)$ were inserted into the reservoirs as electrodes.

Electrophoretic Separation in Multi-channel Microchips. The PVP dynamic coating and PEO sieving matrix 
were hydrodynamically filled using a vacuum pump (EYELA A-3s vacuum aspirator, Tokyo Rikakikai Co., Ltd, Tokyo, Japan) for the three multi-channel microchip reservoirs (reservoir 3) in Figure 1(a) for $5 \mathrm{~min}$, respectively. The sample $(2.0 \mathrm{~mL})$ was then pipetted into the sample inlet reservoir (reservoir 4 in Figure 1(a)) of the microchip and injected into the injection- $\mathrm{T}$ region using a conventional electrokinetic injection method. The injection potential was set as $480 \mathrm{~V}$ at the sample outlet reservoir 2 followed by the grounding sample inlet reservoir 4 for $60 \mathrm{~s}$.

The applied separation electric field strength was stepcontrolled and adjusted in the time domain by DBMA-100 software to range from 100 to $700 \mathrm{~V} / \mathrm{cm}$ between reservoirs 1 and 3. During separation, the maintained voltage (the potential difference between reservoirs 2 and 4) was properly applied according to the separation voltage. After each run, the microchannel was rinsed with water followed by a running buffer for $10 \mathrm{~min}$ each.

Programmed Step Electric Field Strength (PSEFS). The PSEFS separation was optimized as follows. First, constant electric field strength in the range of 100-700 V/cm was used to separate all of the DNA molecules of the DNA ladder. After the separation, the determination of whether PSEFS or a constant electric field strength provided the best results was established. If PSEFS was chosen, we eliminated or decreased the portions of the gradient prior to the first DNA peak (100 bp) and following the last DNA peak (200 bp). Finally, if the separation in the second step was acceptable, the gradient time was decreased to reduce the separation time. The PSEFS was programmed to provide the best separation of target DNA molecules (116 bp and $195 \mathrm{bp}$ DNA) with more than 1.5 of resolution $(R)$.

\section{Results and Discussion}

Optimization of the MCME Separation. Depending on the basic electrophoretic separation theory, the electrophoretic mobility of a DNA molecule directly relies on the applied electric field:

$$
v_{e p}=\mu_{e p}(E) \times E
$$

where $v_{\mathrm{ep}}$ is the electrophoretic velocity, $\mu_{e p}$ is the electrophoretic mobility, and $E$ is the applied electric field. Hence, increasing the applied electric field strength is a way to significantly increase electrophoretic velocity and decrease separation time (Figures 2(a) and 2(b)). However, due to Ohm's law, the higher applied electric field will induce a higher current and more Joule heating, which will decrease the resolution of the analytes. Additionally, at high applied electric field conditions, the electrophoretic properties of the DNA molecules become electric-field dependent, especially for large DNA molecules (Figures 2(a) and 2(b)). The applied electric field was increased from $138 \mathrm{~V} / \mathrm{cm}$ (Figure 2(a)) to $630 \mathrm{~V} / \mathrm{cm}$ (Figure 2(b)). As a result, the migration times of $100 \mathrm{bp}$ and $200 \mathrm{bp}$ DNA molecules were decreased from $97.3 \mathrm{~s}$ and $106.6 \mathrm{~s}$ to $16.5 \mathrm{~s}$ and $18.3 \mathrm{~s}$, respectively. However, as the electropherogram demonstrates, the re-
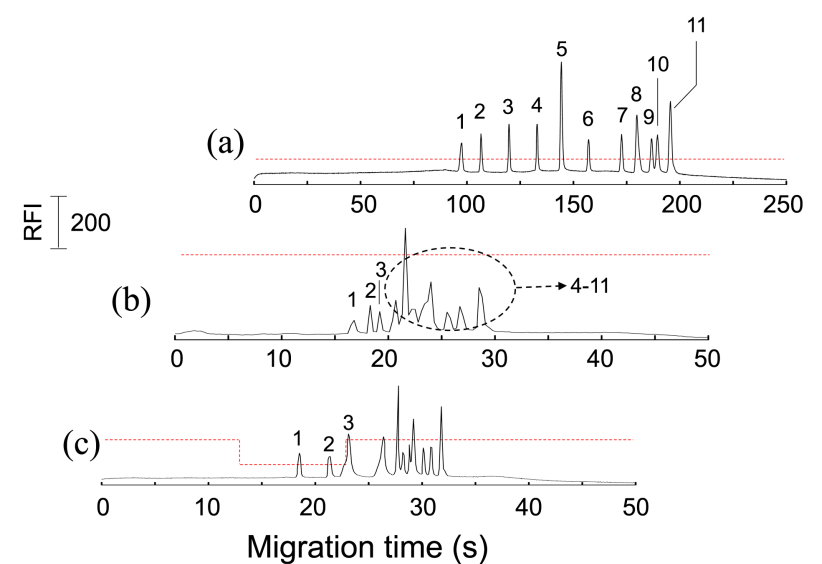

Figure 2. Electropherograms of the 100-bp DNA ladder in the MCME system. (a) Low constant electric field strength (LCEFS) for separation, (b) high constant electric field strength (HCEFS), and (c) programmed step electric field strength (PSEFS) for separation. Separation conditions: running buffer, $1 \times$ TBE buffer $(\mathrm{pH} 8.4)$ with $0.5 \mathrm{ppm}$ EtBr; coating matrix, $1.0 \%$ PVP $\left(M_{\mathrm{r}}=\right.$ $1,000,000)$; sieving matrix, $0.3 \%$ PEO $\left(M_{\mathrm{r}}=8,000,000\right)$; DNA ladder concentration, $14.4 \mathrm{ng} / \mathrm{mL}$; applied separation electric field, (a) $138 \mathrm{~V} / \mathrm{cm}$, (b) $630 \mathrm{~V} / \mathrm{cm}$, (c) $615 \mathrm{~V} / \mathrm{cm}$ from 0 to $13 \mathrm{~s}, 300 \mathrm{~V} /$ $\mathrm{cm}$ from 13 to $23 \mathrm{~s}, 615 \mathrm{~V} / \mathrm{cm}$ from 23 to $50 \mathrm{~s}$. Peaks: $1=100 \mathrm{bp}, 2$ $=200 \mathrm{bp}, 3=300 \mathrm{bp}, 4=400 \mathrm{bp}, 5=500 \mathrm{bp}, 6=600 \mathrm{bp}, 7=800$ bp, $8=1,000$ bp, $9=1,500$ bp, $10=2,000$ bp, $11=3,000$ bp. RFI, relative fluorescence intensity.

solutions of specific DNA molecules were decreased dramatically, especially for large DNA molecules. We considered that the low resolution of large DNA molecules ( $>400 \mathrm{bp}$ ) was caused by the entanglement of DNA molecules under high electric field strength. According to the biased reputation mechanism, the electrophoretic mobility of a DNA molecule not only relies on its molecular size, but also relies on the applied electric field:

$$
\mu_{e p} \approx \frac{1}{N}+b E^{2}
$$

where $N$ is the DNA molecular size and $b$ is a constant. ${ }^{27}$ The Eq. (2) clearly describes that the high applied electric field can increase the electrophoretic mobility of given DNA molecules remarkably. However, for large DNA molecules, the value of $1 / N$ will be much smaller than $b E^{2}(1 / N<<$ $b E^{2}$ ); hence the larger DNA molecules bring higher sensitivity based on the biased reputation mechanism. Therefore, the resolutions of large DNA molecules under high applied electric field strength remarkably decreased and a loss of baseline separation was observed (peaks 4-11 in Figure 2(b)).

MCME Separation with PSEFS. Since the migration time and resolution of a given analyte are highly dependent on the applied electric field, applying a PSEFS during separation will be an easy method to decrease the analysis time without a loss of resolution. The conditions for PSEFS were optimized as follows. First, we determined the low constant electric field strength required for the separation of all DNA molecules. Second, we applied a high-strength constant electric field. Next, we decreased the electric field 
strength at specific domains. Finally, if the separation achieved during the third step was deemed acceptable, we reduced the gradient time. By applying high and constant electric field strength in a non-related region of the DNA ladder, the DNA molecules traveled across the separation channel at high speed, thereby remarkably decreasing the analysis time. In contrast, the relatively low electric field which was applied in the region of interest could decrease the migration speed of specific DNA molecules and increase the separation efficiency and resolution. Thus, as programming the step electric field strength in the time domain, the ultra-fast separation of specific small DNA molecules without any loss of resolution was achieved. After optimization, the best PSEFS conditions for the fast separation of 100- and 200-bp DNA molecules were determined at $615 \mathrm{~V} / \mathrm{cm}$ from $0 \mathrm{~s}$ to $13 \mathrm{~s}, 300 \mathrm{~V} / \mathrm{cm}$ from $13 \mathrm{~s}$ to $23 \mathrm{~s}$ and $615 \mathrm{~V} / \mathrm{cm}$ from $23 \mathrm{~s}$ to $50 \mathrm{~s}$ (Figure 2(c)). The migration times of 100-bp and 200bp DNA molecules were $18.5 \mathrm{~s}$ and $21.5 \mathrm{~s}$, respectively, and the resolution of $100 / 200 \mathrm{bp}$ was 4.7 . This result indicates that the PSEFS protocol can decrease the migration time without any loss of resolution.

Parallel Detection of Various H1N1 Virus DNAs by MCME/PSEFS. Due to its analysis speed and resolution, MCME/PSEFS was determined to be an adequate method to analyze the PCR products of H1N1 virus. Figure 3 shows the representative electropherograms of the PCR products of H1N1 virus obtained by conventional SGE (Figure 3(a)) and MCME/PSEFS (Figure 3(b)). In the MCME/PSEFS method,

(a)

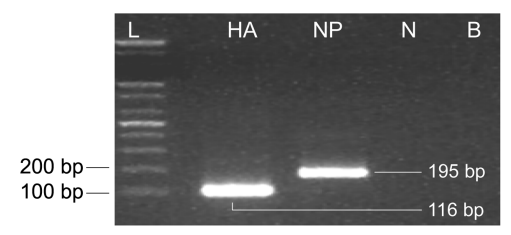

(b)

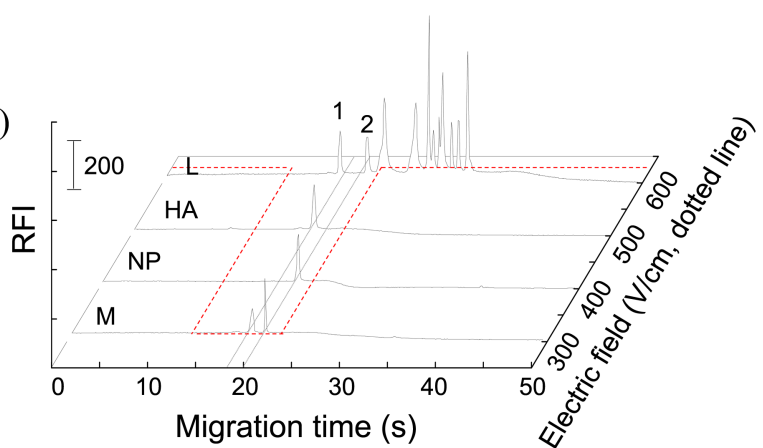

Figure 3. (a) Representative slab gel electrophoresis electropherograms of amplified PCR products for the H1N1 virus from infected humans and (b) after using PSEFS in MCME. SGE conditions: $2.0 \%$ agarose gel matrix in $1 \times$ TAE buffer $(\mathrm{pH} 8.4)$; applied voltage, $150 \mathrm{~V}$ for $50 \mathrm{~min}$; temperature, ambient. MCME/PSEFS condition, running buffer, $1 \times$ TBE buffer $(\mathrm{pH} 8.4)$ with $0.5 \mathrm{ppm}$ EtBr; coating matrix, $1.0 \% \operatorname{PVP}\left(M_{\mathrm{r}}=1,000,000\right)$; sieving matrix, $0.3 \%$ PEO $\left(M_{\mathrm{r}}=8,000,000\right)$; PSEFS, $615 \mathrm{~V} / \mathrm{cm}$ from 0 to $13 \mathrm{~s}, 300$ $\mathrm{V} / \mathrm{cm}$ from 13 to $23 \mathrm{~s}, 615 \mathrm{~V} / \mathrm{cm}$ from 23 to $50 \mathrm{~s}$. L = DNA ladder, $\mathrm{HA}=$ hemagglutinin gene $\mathrm{PCR}$ product $(116 \mathrm{bp}), \mathrm{NP}=$ nucleocapsid protein gene PCR product (195 bp), $\mathrm{N}=$ negative control, $\mathrm{B}$ $=$ blank control; $\mathrm{M}=\mathrm{HA}$ and $\mathrm{NP}$ sample mixture (HA:NP $=1: 1$ ). Peaks: $1=100 \mathrm{bp}, 2=200 \mathrm{bp}$. RFI, relative fluorescence intensity.

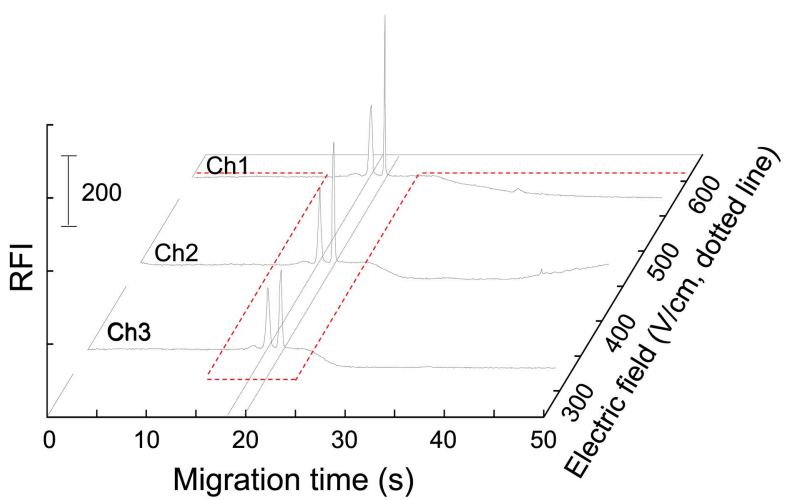

Figure 4. High-throughput performance of the MCME/PSEFS method with amplified PCR products mixture of HA and NP (HA:NP = 1:1) for the H1N1 virus from infected humans. MCME/ PSEFS conditions, running buffer, $1 \times$ TBE buffer $(\mathrm{pH} 8.4)$ with $0.5 \mathrm{ppm}$ EtBr; coating matrix, 1.0\% PVP $\left(M_{\mathrm{r}}=1,000,000\right)$; sieving matrix, $0.3 \%$ PEO $\left(M_{\mathrm{r}}=8,000,000\right)$; PSEFS, $615 \mathrm{~V} / \mathrm{cm}$ from 0 to $13 \mathrm{~s}, 300 \mathrm{~V} / \mathrm{cm}$ from 13 to $23 \mathrm{~s}, 615 \mathrm{~V} / \mathrm{cm}$ from 23 to $50 \mathrm{~s}$. Ch1 = channel $1 ; \mathrm{Ch} 2=$ channel $2 ; \mathrm{Ch} 3=$ channel $3 . \mathrm{RFI}$, relative fluorescence intensity.

the 100-bp DNA ladder, the HA gene PCR product and the NP gene PCR product from the H1N1 virus are analyzed simultaneously. By applying programmed electric fields $(615 \mathrm{~V} / \mathrm{cm}$ from $0 \mathrm{~s}$ to $13 \mathrm{~s}, 300 \mathrm{~V} / \mathrm{cm}$ from $13 \mathrm{~s}$ to $23 \mathrm{~s}$, and $615 \mathrm{~V} / \mathrm{cm}$ from $23 \mathrm{~s}$ to $50 \mathrm{~s}$ ), the HA and NP PCR products are detected at $19.5 \mathrm{~s}$ and $20.9 \mathrm{~s}$ respectively. Additionally, the HA and NP gene PCR products mixture (HA:NP = 1:1) was separated within $21 \mathrm{~s}$ with the 1.8 resolution. In addition, the MCME/PSEFS method was applied with H1N1 virus infected Madin-Darby Canine Kidney (MDCK) cells from National Culture Collection for Pathogens (NCCP, Osong-eup, Korea) to demonstrate the application for field diagnosis. The PCR products of the clinical samples were detected at same times of the HA and NP PCR products and diagnosed within $21 \mathrm{~s}$ (Supporting information, Figure S1 and Table S1).

High-throughput Screening Based on Simultaneous Detection in Multi-channel. To increase the throughput, three H1N1 gene PCR products mixture (HA:NP = 1:1) samples were introduced in parallel microchannels and separated simultaneously. After applying the optimal MCME/ PSEFS condition, the HA gene PCR products were analyzed within $21 \mathrm{~s}$ with a three-fold throughput (Figure 4). The NP gene PCR products were analyzed in a similar fashion. With-

Table 1. Comparison of migration time and peak area of specific DNA molecules and PCR products of the H1N1 virus by the multichannel microchip electrophoresis method with a programmed step electric field strength

\begin{tabular}{cccc}
\hline & Migration time (s) & Peak area & Resolution \\
\hline $100 \mathrm{bp}$ & $18.5 \pm 0.2$ & $263.4 \pm 2.8$ & $4.7 \pm 0.2$ \\
$200 \mathrm{bp}$ & $21.5 \pm 0.1$ & $281.2 \pm 5.4$ & \\
HA (116 bp) & $19.5 \pm 0.1$ & $205.8 \pm 6.5$ & $1.8 \pm 0.1$ \\
NP (195 bp) & $20.9 \pm 0.1$ & $223.6 \pm 6.8$ & \\
\hline
\end{tabular}

The data are presented as mean \pm standard deviation $(n=3)$. 
out allowing any cross-talk between neighboring separation channels, the samples in the three channels were analyzed in parallel. The design of the separation channels on the microchip prevents the problem of leakage from the microchip reservoirs or the channel and the distance between the channels provides sufficient isolation of individual separation channels. Additionally, the lack of cross-talk between separation channels ensured the high precision of this method (Table 1). These results indicated that the MCME/ PSEFS protocol was not only fast and high-throughput, but also very precise.

\section{Conclusion}

A fast and high-throughput detection method for H1N1 virus DNA based on multi-channel microchip electrophoretic separation with PSEFS was investigated. By studying the applied electric field strength and DNA molecular separation electropherograms during the MCME separation process, the PSEFS method was developed and optimized to separate 100- and 200-bp DNA molecules along with a 100-bp DNA ladder in $\sim 20 \mathrm{~s}$ without any loss of resolution. Afterward, based on MCME/PSEFS method, the HA and NP PCR products mixture of the H1N1 virus (116 bp and $195 \mathrm{bp}$ ) were separated within $19.5 \pm 0.1 \mathrm{~s}$ and $20.9 \pm 0.1 \mathrm{~s}$, respectively, which is $\sim 20$ times faster than conventional SGE methods. MCME/PSEFS demonstrated high-throughput analysis of H1N1 virus-related DNA molecules with high precision and without any loss of resolution. We believe that with the development of additional microelectromechanical or nanoelectromechanical methods, the integration of more separation channels onto a single wafer will be possible and will allow for higher throughputs in the future.

Acknowledgments. The authors thank Ahram Biosystem Incorporated for providing H1N1 virus DNA samples. This work was supported by a grant from Kyung Hee University in 20130573.

\section{References}

1. Castillo-Salgado, C. Epidemiol. Rev. 2010, 32, 93.

2. Ghebremedhin, B.; Engelmann, I.; Konig, W.; Konig, B. J. Med.
Microbiol. 2009, 58, 365 .

3. Taylor, J.; McPhie, K.; Druce, J.; Birch, C.; Dwyer, D. E. J. Med. Virol. 2009, 81, 1918.

4. Kwon, D.; Shin, K.; Kwon, M.; Oh, H. B.; Kang, C.; Lee, J. Y. J. Clin. Microbiol. 2011, 49, 437.

5. Tsao, K. C.; Kuo, Y. B.; Huang, C. G.; Chau, S. W.; Chan, E. C. J. Virol. Methods 2011, 173, 387.

6. Wenzel, J. J.; Walch, H.; Bollwein, M.; Niller, H. H.; Ankenbauer, W.; Mauritz, R.; Holtke, H. J.; Zepeda, H. M.; Wolf, H.; Jilg, W.; Reischl, U. Clin. Chem. 2009, 55, 2218.

7. Bose, M. E.; Beck, E. T.; Ledeboer, N.; Kehl, S. C.; Jurgens, L. A.; Patitucci, T.; Witt, L.; LaGue, E.; Darga, P.; He, J.; Fan, J.; Kumar, S.; Henrickson, K. J. J. Clin. Microbiol. 2009, 47, 2779.

8. He, J.; Bose, M. E.; Beck, E. T.; Fan, J.; Tiwari, S.; Metallo, J.; Jurgens, L. A.; Kehl, S. C.; Ledeboer, N.; Kumar, S.; Weisburg, W.; Henrickson, K. J. J. Clin. Microbiol. 2009, 47, 2772.

9. Hamelin, M. E.; Baz, M.; Abed, Y.; Couture, C.; Joubert, P.; Beaulieu, E.; Bellerose, N.; Plante, M.; Mallett, C.; Schumer, G.; Kobinger, G. P.; Boivin, G. PLoS Path. 2010, 6, e1001015.

10. Furuse, Y.; Odagiri, T.; Okada, T.; Khandaker, I.; Shimabukuro, K.; Sawayama, R.; Suzuki, A.; Oshitani, H. J. Virol. Methods 2010, 168, 94

11. Amano, Y.; Cheng, Q. Anal. Bioanal. Chem. 2005, 381, 156.

12. Patolsky, F.; Zheng, G.; Hayden, O.; Lakadamyali, M.; Zhuang, X.; Lieber, C. M. Proc. Natl. Acad. Sci. USA 2004, 101, 14017.

13. Manz, A.; Harrison, D. J.; Verpoorte, E. M. J.; Fettinger, J. C.; Paulus, A.; Luedi, H.; Widmer, H. M. J. Chromatogr. 1992, 593, 253.

14. Woolley, A. T.; Mathies, R. A. Anal. Chem. 1995, 67, 3676.

15. Schmalzing, D.; Adourian, A.; Koutny, L.; Ziaugra, L.; Matsudaira, P.; Ehrlich, D. Anal. Chem. 1998, 70, 2303.

16. Backhouse, C.; Caamano, M.; Oaks, F.; Nordman, E.; Carrillo, A.; Johnson, B.; Bay, S. Electrophoresis 2000, 21, 150.

17. Khandurina, J.; Guttman, A. Curr. Opin. Chem. Biol. 2003, 7, 595.

18. Zhang, L. H.; Dang, F. Q.; Baba, Y. J. Pharmaceut. Biomed. 2003, 30, 1645 .

19. Kang, S. H.; Gong, X. Y.; Yeung, E. S. Anal. Chem. 2000, 72, 3014.

20. Vilkner, T.; Janasek, D.; Manz, A. Anal. Chem. 2004, 76, 3373.

21. Mann, M.; Hendrickson, R. C.; Pandey, A. Annu. Rev. Biochem. 2001, 70, 437.

22. Gygi, S. P.; Rist, B.; Gerber, S. A.; Turecek, F.; Gelb, M. H.; Aebersold, R. Nat. Biotechnol. 1999, 17, 994.

23. Pandey, A.; Mann, M. Nature 2000, 405, 837.

24. Gallop, M. A.; Barrett, R. W.; Dower, W. J.; Fodor, S. P.; Gordon, E. M. J. Med. Chem. 1994, 37, 1233.

25. Gordon, E. M.; Barrett, R. W.; Dower, W. J.; Fodor, S. P.; Gallop, M. A. J. Med. Chem. 1994, 37, 1385.

26. Ecker, D. J.; Crooke, S. T. Biotechnology (N. Y.) 1995, 13, 351.

27. Dorfman, K. D.; King, S. B.; Olson, D. W.; Thomas, J. D.; Tree, D. R. Chem. Rev. 2013, 113, 2584. 